\title{
Differences in the Effects in the Newborn Piglet of Various Nonsteroidal Antiinflammatory Drugs on Cerebral Blood Flow but Not on Cerebrovascular Prostaglandins
}

\author{
SYLVAIN CHEMTOB, KAE BEHARRY, THOMAS BARNA, DAYA R. VARMA, AND \\ JACOB V. ARANDA
}

University of Iowa Hospitals and Clinics, Department of Pediatrics, Iowa City, Iowa 52242 and Montreal Children's Hospital, Department of Developmental Pharmacology and Therapeutics, and the Department of Pharmacology and Therapeutics, McGill University, Montreal, Canada H3H-IP3

\begin{abstract}
To characterize the role of prostaglandins (PG) in the regulation of basal cerebral blood flow (CBF) in the newborn, we determined the effects of four nonsteroidal antiinflammatory drugs, indomethacin $(3 \mathrm{mg} / \mathrm{kg}, n$ $=8$ and $10 \mathrm{mg} / \mathrm{kg}, n=5)$, aspirin $(65 \mathrm{mg} / \mathrm{kg}, n=6)$, ibuprofen $(30 \mathrm{mg} / \mathrm{kg}, n=8)$, and naproxen $(15 \mathrm{mg} / \mathrm{kg}, n$ $=6$ ), on $\mathrm{CBF}$, cerebral metabolism, and cerebrovascular PG in conscious 1- to 3-d-old piglets. Drugs and vehicle ( $n$ $=8$ ) were injected i.v., and measurements were made 5 min before and 20 and $60 \mathrm{~min}$ after injections. Neither the vehicle nor any of the nonsteroidal antiinflammatory drugs exerted significant effects on mean arterial blood pressure and on blood gases and $\mathrm{pH}$. All four drugs, with the exception of indomethacin at the lower dose $(3 \mathrm{mg} / \mathrm{kg})$, decreased PG to nearly undetectable levels within $20 \mathrm{~min}$; the low dose of indomethacin caused a small decrease (18$32 \%$ ) in PG at $60 \mathrm{~min}$. However, the effects of these agents on CBF were diverse. CBF increased after the administration of aspirin, decreased to almost the same extent after both low and high doses of indomethacin, and did not change after the administration of ibuprofen and naproxen. Cerebral metabolic rate for oxygen was increased by aspirin but was unaltered by the other drugs. The data suggest that PG may not play a critical role in the regulation of basal CBF in the newborn animal and that certain nonsteroidal antiinflammatory drugs may have additional actions unrelated to the inhibition of PG synthesis. (Pediatr Res 30: 106-111, 1991)
\end{abstract}

Abbreviations

PG, prostaglandin

$\mathrm{CBF}$, cerebral blood flow

BP, blood pressure

NSAID, nonsteroidal antiinflammatory drug

The role of $\mathrm{PG}$ in the regulation of $\mathrm{CBF}$ during various hemodynamic disturbances, such as hypertension, hypotension, hypoxia, and asphyxia, has been reported by various investigators (1-14). However, the significance of $P G$ in the regulation of basal CBF remains controversial (15-19). In most studies ex-

Received November 20, 1990; accepted March 4, 1991.

Correspondence: Sylvain Chemtob, M.D., Ph.D., F.R.C.P.C., University of Iowa Hospitals \& Clinics, Department of Pediatrics, Iowa City, IA 52242

Supported in part by the Medical Research Council of Canada. amining the role of PG in cerebral hemodynamics, indomethacin has been used as the prototype of nonsteroidal antiinflammatory drugs (NSAID) $(20,21)$. However, the extremely fast onset of action of indomethacin on the cerebral circulation $(15-19,22)$ does not coincide with its effects on the cerebral and vascular levels $(23,24)$ and the disposition $(25,26)$ of $\mathrm{PG}$.

Therapeutic doses of indomethacin $(0.2 \mathrm{mg} / \mathrm{kg})$ have been shown to decrease CBF and CBF velocity in the human infant within 2 min (16-19), long before any decrease in arterial or cerebral PG occurs $(23,24)$. Our recent data suggest that the effects of indomethacin are not identical to those of other NSAID, such as ibuprofen $(12,13)$, and may not be produced entirely by an inhibition of cyclooxygenase activity $(12,27-30)$. Also, the effects of salicylates on cerebral hemodynamics of adults do not correspond with their effects on the synthesis of PG (31). In short, the role of PG in the regulation of basal blood flow to major organs remains controversial (32). We therefore determined the effects of four NSAID, namely, indomethacin, aspirin, ibuprofen, and naproxen, on CBF and cerebrovascular PG, using the conscious newborn piglet as the experimental model. We found that although all NSAID inhibited the synthesis of PG, CBF was increased by aspirin, decreased by indomethacin, and not affected by ibuprofen and naproxen.

\section{MATERIALS AND METHODS}

This study was approved by the Animal Care and Ethics Committee of the McGill University-Montreal Children's Hospital Research Institute and the University of Iowa Animal Care and Use Committee.

Surgical preparation. Experiments were conducted on 41 newborn piglets $(1.2-2 \mathrm{~kg}), 1$ to $3 \mathrm{~d}$ old. The catheterization of the blood vessels was done under halothane anesthesia, as previously described (12-14). A polyethylene catheter was placed into the left ventricle via the right subclavian artery for the injection of radiolabeled microspheres. The left subclavian artery was catheterized for continuous recording of BP by means of a pressure transducer (Statham, Glen Burnie, MD) connected to a multichannel recorder (DR-8; Electronics for Medicine, White Plains, NY). The femoral artery was cannulated for the withdrawal of blood samples including reference samples. A polyethylene catheter (Intramedic, PE-50; Becton Dickinson, Parsippany, NJ) was placed into the inferior vena cava via the femoral vein for drug injection, and the sagittal vein was cannulated through a burr hole in the skull for blood sampling.

After catheterization, the animals were allowed to recover from anesthesia under an overhead lamp for approximately 3 to $4 \mathrm{~h}$. For the purposes of experimentation, the awake and sponta- 
neously breathing animals were placed comfortably on a cloth sling, which did not interfere with breathing movements. Body temperature was maintained at $38^{\circ} \mathrm{C}$ by an infant radiant warmer.

Experimental protocol. Animals were divided randomly to receive i.v. either aspirin $(65 \mathrm{mg} / \mathrm{kg}, n=6)$, ibuprofen $(30 \mathrm{mg} /$ $\mathrm{kg}, n=8)$, naproxen $(15 \mathrm{mg} / \mathrm{kg}, n=6)$, indomethacin $(3 \mathrm{mg} /$ $\mathrm{kg}, n=8$ or $10 \mathrm{mg} / \mathrm{kg}, n=5)$, or vehicle $(n=8)$ in a total volume of approximately 1 to $2 \mathrm{~mL}$. These doses of NSAID were selected because they have been previously shown to inhibit cyclooxygenase activity in the brain and/or alter cerebral hemodynamics $(6,12,13,15,22,23,31,33-38)$.

CBF measurements were made $5 \mathrm{~min}$ before and 20 and 60 min after the administration of the drug or the vehicle. Immediately after each injection of microspheres and after the withdrawal of the reference blood sample, blood was withdrawn from the sagittal vein and left subclavian artery for the determination of blood gases and oxygen saturation of $\mathrm{Hb}$ (Instrumentation Laboratory, Inc., Lexington, MA), concentration of $\mathrm{Hb}$, and assays of plasma $\mathrm{PGE}, \mathrm{PGF}_{2 \alpha}$, and 6-keto-PGF ${ }_{1 \alpha}$ (the stable metabolite of $\mathrm{PGI}_{2}$ ). Withdrawn blood was promptly replaced with blood from a donor piglet. After the experiment, the animal was killed with an administration of pentobarbital. An autopsy was performed to verify the location of catheters and to remove the brain for the counting of microspheres.

Measurement of $C B F$. CBF was measured using the radiolabeled microsphere technique (39), as previously used (12-14). Approximately 300000 microspheres of $15-\mu \mathrm{m}$ diameter labeled with $\left[{ }^{141} \mathrm{Ce}\right],\left[{ }^{51} \mathrm{Cr}\right]$, and $\left[{ }^{46} \mathrm{Sc}\right]$ were injected in a random order into the left ventricle, and the catheter was flushed with $2 \mathrm{~mL}$ of saline. Reference blood samples were withdrawn from the left subclavian catheter, beginning $10 \mathrm{~s}$ before microsphere injection, and were continued for $70 \mathrm{~s}$ at a rate of $2 \mathrm{~mL} / \mathrm{min}$, using a Harvard infusion/withdrawal pump (Harvard Apparatus Co., Inc., S. Natick, MA). The brain was weighed and divided into four major regions: cortex, periventricular area, brainstem, and cerebellum. Radioactivity in the tissues and reference blood samples was counted by a gamma counter (Biogamma II; Beckman Instruments, Inc., Fullerton, CA), with appropriate provision for interference between nuclides. Microspheres were equally distributed to both cerebral hemispheres. In all of the brain regions and reference blood samples, the number of microspheres exceeded 1200, indicating reliable blood-flow measurements (39).

Regional CBF (mL/min/100 g) was calculated using the following formula: $\mathrm{CBF}=\mathrm{cpm} / 100 \mathrm{~g}$ of tissue $\times$ withdrawal rate of reference sample per cpm in the reference sample. Cerebral metabolic rate for oxygen was calculated as $\mathrm{CBF} \times($ arterial sagittal venous $\mathrm{O}_{2}$ content) and expressed in $\mathrm{mL} / \mathrm{min} / 100 \mathrm{~g}$

Assay of $P G$. Arterial and sagittal venous blood samples (1.5 $\mathrm{mL}$ ) were collected in ice-cold polypropylene tubes containing $28 \mathrm{mg} / \mathrm{mL}$ EDTA and $40 \mu \mathrm{g} / \mathrm{mL}$ indomethacin. The blood was immediately centrifuged at $2450 \times g$ for $15 \mathrm{~min}$ at $4^{\circ} \mathrm{C}$, and the plasma was stored at $-70^{\circ} \mathrm{C}$ until it was assayed. PG were measured using RIA (40) kits that were previously tested for reproducibility (12). Plasma proteins were precipitated with acetone at $-20^{\circ} \mathrm{C}$. Neutral lipids were removed with petroleum ether. The aqueous phase was acidified to $\mathrm{pH} 3$ to 4 . PG were extracted with ethyl acetate, which was subsequently evaporated to dryness. The residue was dissolved in a $0.01 \mathrm{M}$ phosphate buffer $(\mathrm{pH} 7$ ) containing $0.1 \%$ bovine gamma globulin and $0.1 \%$ sodium azide.

The aliquots of plasma were assayed in duplicate for total PGE, PGF $_{2 \alpha}$, and 6-keto-PGF $\left.{ }_{1 \alpha} .{ }^{3} \mathrm{H}\right] \mathrm{PG}$ were used for the assays. After an incubation period of $2 \mathrm{~h}$ at $25^{\circ} \mathrm{C}$, the bound analyte was separated from the free analyte, using dextran-coated charcoal. Biofluor was used as the emulsifier-scintillation cocktail. Radioactivity was counted in an automated $\beta$-scintillation counter (Beckman). All antibodies exhibited $<1.6 \%$ cross-reactivity to other PG, with the exception of antibodies to PGE that displayed
$100 \%$ cross-reactivity for $\mathrm{PGE}_{1}$ and $\mathrm{PGE}_{2}$. Recovery was determined, using aliquots of plasma with known concentrations of $\mathrm{PG}$, and was $>80 \%$. The normalized percentage of bound tracer on standard curves varied $<5 \%$ between assays. The standards used to determine these curves allowed measurements of PG in the concentration range of 20 to $20000 \mathrm{pg} / \mathrm{mL}$.

Chemicals and reagents. Indomethacin, aspirin, ibuprofen, and naproxen were purchased from Sigma Chemical Co. (St. Louis, MO), dissolved in $\mathrm{NaCl} 150 \mathrm{mM}$ and $\mathrm{NaOH} 0.3 \mathrm{~N}$, and titrated to $\mathrm{pH}$ 7.4. PG RIA kits were purchased from Advanced Magnetics (Boston, MA), radionuclide-labeled microspheres from 3-M (Newbrighton, MN), and Biofluor from New England Nuclear (Boston, MA). All other chemicals were purchased from Fisher Laboratories (Montreal, Quebec and Springfield, NJ).

Statistical analysis. Data were analyzed using analysis of variance for different groups and repeated measures and comparison among means tests; for regression analysis, the Pearson's productmoment correlation coefficient was determined. A $p$ of less than 0.05 was assumed to denote significant differences. Data were expressed as means \pm SEM and as ranges.

\section{RESULTS}

Stability of experimental preparations. Mean BP and arterial $\mathrm{pH}, \mathrm{PCO}_{2}$, and $\mathrm{PO}_{2}$ remained stable after treatment with the vehicle or any of the NSAID (Table 1; results with the low dose of indomethacin are not shown).

Effects of NSAID on CBF and metabolism. The effects of the various NSAID on total and regional CBF are shown in Figure 1. In the vehicle-, ibuprofen-, and naproxen-treated animals, CBF remained constant throughout the experimental period. In contrast, indomethacin ( 3 and $10 \mathrm{mg} / \mathrm{kg}$ ) decreased total and regional $\mathrm{CBF}$ by 31 to $42 \%$ at 20 and at $60 \mathrm{~min}$ after drug injection ( $p<0.01$ compared with basal values). The changes in CBF observed 20 and 60 min after indomethacin was administered were similar to each other, and there were no differences in these CBF changes when comparing the two doses of indomethacin. Aspirin produced a significant increase $(p<0.05$ compared with basal values) in CBF at 20 min (16-22\%) and a similar rise in CBF at $60 \mathrm{~min}(20-32 \%)$ after its administration. The cerebral metabolic rate for oxygen was increased by $23 \pm$ $2 \%$ and $26 \pm 3 \% 20$ and $60 \mathrm{~min}$, respectively, after the administration of aspirin $(p<0.05$ compared with basal value) but was not affected by any other treatment (Table 2).

Effects of NSAID on PG concentrations. The administration of the vehicle did not change the PG concentrations in the sagittal sinus and arterial plasma (Figs. $2 a$ and $3 a$ ). The $3-\mathrm{mg} / \mathrm{kg}$ dose of indomethacin produced no significant changes in PG concentrations at $20 \mathrm{~min}$ but decreased their concentrations by 18 to $32 \%(p<0.05)$ at $60 \mathrm{~min}$ after the injection (Figs. $2 e$ and $3 e$ ). On the other hand, the higher dose of indomethacin $(10 \mathrm{mg} / \mathrm{kg})$ as well as aspirin $(65 \mathrm{mg} / \mathrm{kg})$, ibuprofen $(30 \mathrm{mg} / \mathrm{kg})$, and naproxen $(15 \mathrm{mg} / \mathrm{kg})$ markedly decreased the concentrations of $\mathrm{PG}$ to nearly undetectable levels of $\mathrm{PGF}_{2 \alpha}$ and 6-keto-PGF $1 \alpha(p<$ 0.001 ) at 20 and $60 \mathrm{~min}$ after their injections; the levels of PG 20 and $60 \mathrm{~min}$ after the administration of these drugs were similar (Figs. $2 b-d$ and $f$ and $3 b-d$ and $f$ ).

The relationship between total $\mathrm{CBF}$ and sagittal sinus PG concentrations was also examined (Fig. 4). There was no correlation between $\mathrm{CBF}$ and any of the PG measured for each of the individual treatment groups or for the combination of these groups $(r=-0.31-0.25, p>0.24)$.

\section{DISCUSSION}

To find out whether or not an inhibition of PG synthesis by different NSAID produced similar effects on CBF, we administered indomethacin, aspirin, ibuprofen, and naproxen at doses expected to completely inhibit the synthesis of $P G$ in the cerebral spinal fluid or brain $(23,31,33,37,38)$ as well as a lower dose 
Table 1. Effects of vehicle and different nonsteroidal antiinflammatory drugs on blood pressure and gases of conscious newborn piglets*

\begin{tabular}{|c|c|c|c|c|c|}
\hline \multirow[b]{2}{*}{ Agent } & \multirow{2}{*}{$\begin{array}{c}\text { Dose } \\
(\mathrm{mg} / \mathrm{kg})\end{array}$} & \multirow[b]{2}{*}{ Parameters } & \multirow[b]{2}{*}{ Basal } & \multicolumn{2}{|c|}{ Time after injection of agent } \\
\hline & & & & $20 \mathrm{~min}$ & $60 \mathrm{~min}$ \\
\hline \multirow[t]{4}{*}{ Vehicle } & & MBP & $8.02 \pm 0.62$ & $8.69 \pm 0.40$ & $7.63 \pm 0.39$ \\
\hline & & $\mathrm{pH}$ & $7.42 \pm 0.02$ & $7.46 \pm 0.03$ & $7.47 \pm 0.03$ \\
\hline & & $\mathrm{PO}_{2}$ & $9.86 \pm 0.83$ & $9.63 \pm 0.67$ & $9.04 \pm 0.99$ \\
\hline & & $\mathrm{PCO}_{2}$ & $5.04 \pm 0.29$ & $4.54 \pm 0.28$ & $4.65 \pm 0.36$ \\
\hline \multirow{4}{*}{ Aspirin } & 65 & MBP & $8.55 \pm 0.77$ & $8.16 \pm 0.92$ & $8.29 \pm 0.97$ \\
\hline & & $\mathrm{pH}$ & $7.37 \pm 0.05$ & $7.36 \pm 0.04$ & $7.36 \pm 0.05$ \\
\hline & & $\mathrm{PO}_{2}$ & $12.15 \pm 0.77$ & $12.59 \pm 1.00$ & $13.00 \pm 0.85$ \\
\hline & & $\mathrm{PCO}_{2}$ & $4.99 \pm 0.55$ & $4.75 \pm 0.71$ & $4.49 \pm 0.90$ \\
\hline \multirow[t]{4}{*}{ Ibuprofen } & 30 & MBP & $9.61 \pm 0.52$ & $10.26 \pm 0.55$ & $9.61 \pm 0.53$ \\
\hline & & $\mathrm{pH}$ & $7.41 \pm 0.02$ & $7.39 \pm 0.02$ & $7.37 \pm 0.02$ \\
\hline & & $\mathrm{PO}_{2}$ & $11.66 \pm 1.11$ & $11.49 \pm 1.67$ & $10.92 \pm 1.29$ \\
\hline & & $\mathrm{PCO}_{2}$ & $5.21 \pm 0.37$ & $5.71 \pm 0.60$ & $5.63 \pm 0.77$ \\
\hline \multirow[t]{4}{*}{ Naproxen } & 15 & MBP & $9.21 \pm 0.66$ & $9.48 \pm 0.78$ & $9.08 \pm 0.65$ \\
\hline & & $\mathrm{pH}$ & $7.40 \pm 0.04$ & $7.41 \pm 0.03$ & $7.39 \pm 0.03$ \\
\hline & & $\mathrm{PO}_{2}$ & $10.90 \pm 1.16$ & $10.50 \pm 1.25$ & $11.20 \pm 1.09$ \\
\hline & & $\mathrm{PCO}_{2}$ & $4.84 \pm 0.58$ & $5.08 \pm 0.67$ & $5.33 \pm 0.61$ \\
\hline \multirow[t]{4}{*}{ Indomethacin } & 10 & MBP & $8.03 \pm 0.52$ & $7.77 \pm 1.03$ & $8.95 \pm 0.51$ \\
\hline & & $\mathrm{pH}$ & $7.36 \pm 0.03$ & $7.36 \pm 0.04$ & $7.38 \pm 0.03$ \\
\hline & & $\mathrm{PO}_{2}$ & $12.53 \pm 0.60$ & $11.70 \pm 0.93$ & $11.86 \pm 0.43$ \\
\hline & & $\mathrm{PCO}_{2}$ & $5.08 \pm 0.40$ & $4.86 \pm 0.65$ & $4.78 \pm 0.53$ \\
\hline
\end{tabular}

* Values are mean \pm SEM, expressed in $\mathrm{kPa}(1 \mathrm{~mm} \mathrm{Hg}=0.13 \mathrm{kPa})$, except for $\mathrm{pH}$. Analysis of variance for repeated measures was performed to test for statistical significance. MBP, mean arterial blood pressure.

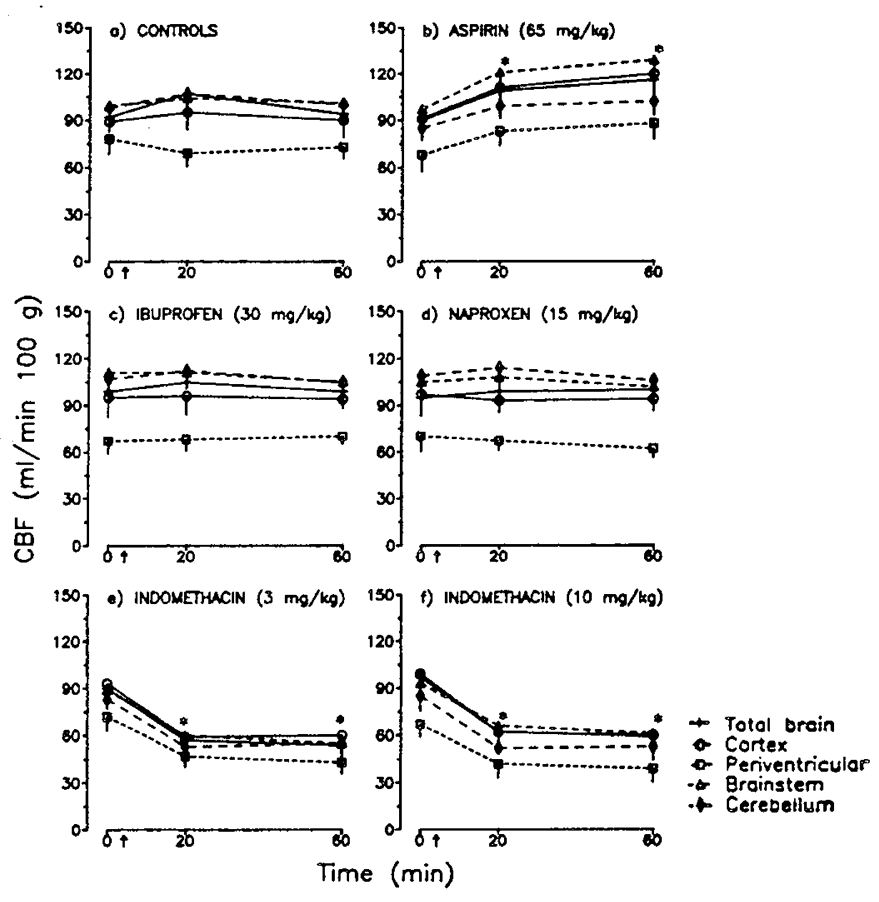

Fig. 1. Effects of aspirin, ibuprofen, naproxen, indomethacin, and vehicle on $\mathrm{CBF}$ of 1 - to 3 -d-old conscious piglets. The 0 time refers to preinjection values. Aspirin $(n=6)$, ibuprofen $(n=8)$, naproxen $(n=$ 6 ), indomethacin ( $n=8$ for $3 \mathrm{mg} / \mathrm{kg}$ and $n=5$ for $10 \mathrm{mg} / \mathrm{kg}$ ), and vehicle $(n=8)$ were injected $5 \mathrm{~min}$ later, as indicated by the arrows. Values are mean \pm SEM. ${ }^{*}, p<0.05$ compared with preinjection values (by analysis of variance for repeated measures and comparison among means tests)

( $3 \mathrm{mg} / \mathrm{kg}$ ) of indomethacin expected to minimally change PG concentrations up to $1 \mathrm{~h}(12,23)$. As discussed below and illustrated in Figure 4, our data show that the effects of different NSAID on cerebral hemodynamics do not correlate with those of PG.

The mean arterial $\mathrm{BP}$ and blood $\mathrm{pH}, \mathrm{PCO}_{2}$, and $\mathrm{PO}_{2}$ of piglets
Table 2. Effects of vehicle and different nonsteroidal antiinflammatory drugs on cerebral metabolic rate for oxygen of conscious newborn piglets*

\begin{tabular}{|c|c|c|c|c|}
\hline \multirow[b]{2}{*}{ Agent } & \multirow{2}{*}{$\begin{array}{c}\text { Dose } \\
(\mathrm{mg} / \mathrm{kg})\end{array}$} & \multirow[b]{2}{*}{ Basal } & \multicolumn{2}{|c|}{$\begin{array}{c}\text { Time after injection of } \\
\text { agent }\end{array}$} \\
\hline & & & $20 \mathrm{~min}$ & $60 \mathrm{~min}$ \\
\hline Vehicle & & $4.0 \pm 0.7$ & $3.8 \pm 0.5$ & $3.8 \pm 0.6$ \\
\hline Aspirin & 65 & $3.7 \pm 0.5$ & $4.5 \pm 0.5 \dagger$ & $4.8 \pm 0.6 \dagger$ \\
\hline Ibuprofen & 30 & $3.2 \pm 0.7$ & $3.0 \pm 1.0$ & $3.4 \pm 0.8$ \\
\hline Naproxen & 15 & $3.4 \pm 0.6$ & $3.7 \pm 0.8$ & $3.6 \pm 0.7$ \\
\hline Indomethacin & 3 & $4.2 \pm 1.1$ & $4.2 \pm 0.9$ & $4.0 \pm 0.7$ \\
\hline Indomethacin & 10 & $3.9 \pm 0.9$ & $3.5 \pm 1.0$ & $4.1 \pm 0.9$ \\
\hline
\end{tabular}

* Values are mean $\pm \mathrm{SEM}$, expressed in $\mathrm{mL} / \mathrm{min} / 100 \mathrm{~g}$

$\dagger p<0.05$ compared to basal value (by analysis of variance for repeated measures and comparison among means tests).

used in this study did not change after the administration of the vehicle or any of the four NSAID; these variables were similar in all of the six groups of experiments and at all three periods of observation (Table 1). Moreover, blood gases, PG concentrations, and hemodynamic parameters remained stable throughout the duration of the experiment in vehicle-treated animals, and these as well as the other measurements taken before administration of the drugs (basal values) were comparable with data in the literature (Tables 1 and 2; Figs. $1 a, 2 a$, and $3 a)(1,2,5-8,12-$ $14,34,37)$. This would suggest that the experimental conditions were suitable for purposes of our study. Nevertheless, the stressful experimental conditions may be a limitation of these studies.

Sagittal sinus blood concentrations of PG were assayed because these have been suggested to reflect levels in specific organ vasculature and may better disclose their role as chemical mediators in organ blood-flow regulation (41-43). Also, no change in sagittal sinus and arterial blood PG concentrations was observed after three (Figs. $2 a$ and $3 a$ ) or four (12) injections of microspheres in vehicle-treated animals, indicating that this number of microsphere injections does not alter cerebrovascular PG concentrations. In support of these inferences, the levels of PG we observed in the sagittal sinus were similar to those previously reported at the same site $(13,34)$ as well as in the cerebral spinal 


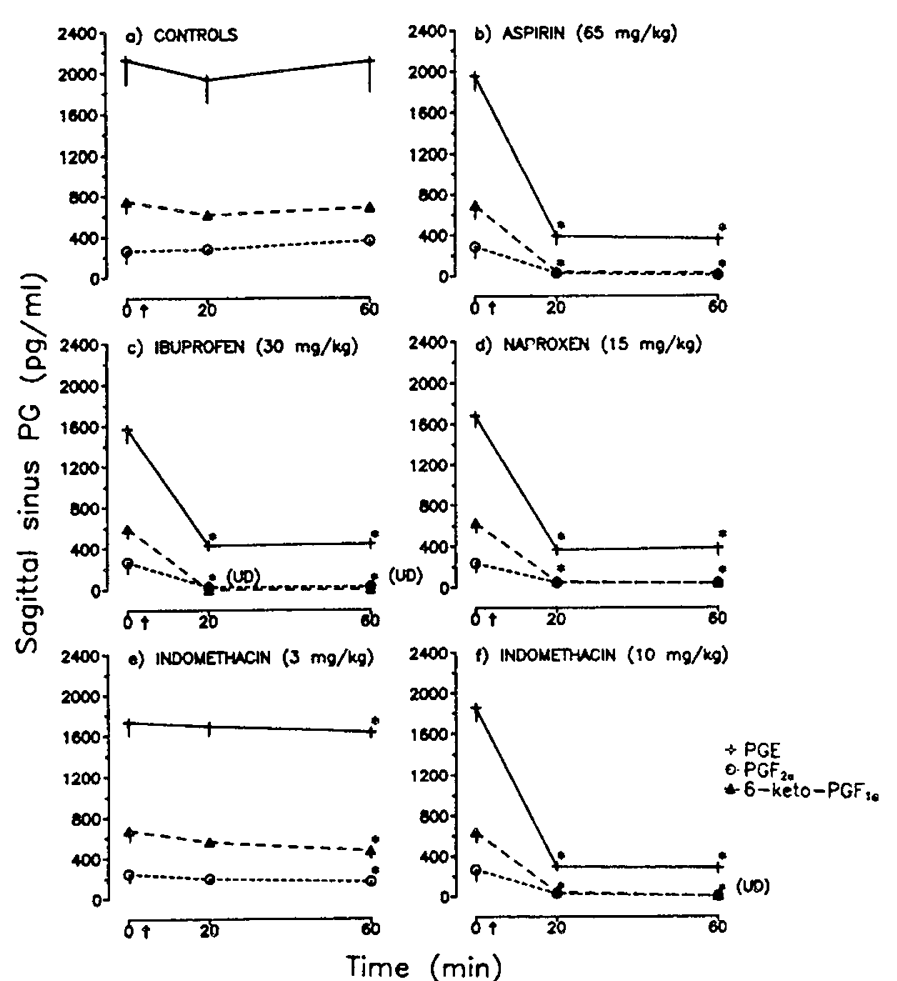

Fig. 2. Effects of aspirin, ibuprofen, naproxen, indomethacin, and vehicle on sagittal sinus concentrations of PG of 1- to 3-d-old conscious piglets. The 0 time refers to preinjection values. Aspirin $(n=6)$, ibuprofen $(n=8)$, naproxen $(n=6)$, indomethacin $(n=8$ for $3 \mathrm{mg} / \mathrm{kg}$ and $n=5$ for $10 \mathrm{mg} / \mathrm{kg})$, and vehicle $(n=8)$ were injected $5 \mathrm{~min}$ later, as indicated by the arrows. Values are mean \pm SEM. $U D$, undetectable levels $(<20$ $\mathrm{pg} / \mathrm{mL}$ ). ${ }^{*}, p<0.05$ compared with preinjection values (by analysis of variance for repeated measures and comparison among means tests).

fluid of both acutely instrumented animals and animals that were instrumented on a long-term basis $(6,37,38)$. This would suggest that sagittal sinus concentrations reflect cerebral and not arterial PG levels (Figs. 2 and 3). Moreover, the PG with the highest levels in the sagittal sinus was PGE (Fig. 2), as reported for the cerebral spinal fluid $(37,44)$, in contrast to the arterial blood, where 6-keto-PGF ${ }_{1 \alpha}$ exhibited the highest concentrations (Fig. 3) $(6,7)$. Thus, based on the levels of PG in the sagittal sinus blood, which seems to reflect those in the cerebral spinal fluid, and the doses of NSAID selected, which have been shown to inhibit cerebral PG synthesis $(6,23,31,33,37,38)$, we believe that brain and cerebral spinal fluid PG levels were decreased by the NSAID used in this study.

Ibuprofen and naproxen markedly decreased PG concentrations in the sagittal sinus to levels reported in the cerebrospinal fluid and brain $(23,33)$ but did not change basal CBF (Figs. 13). Our findings are in accordance with other studies that have shown that ibuprofen does not reduce basal blood flow to the brain $(13,34)$ nor to other major organs (renal, cardiac, and mesenteric) (45-48). PGE and $\mathrm{PGI}_{2}$ are the predominant $\mathrm{PG}$ produced by the brain tissue and cerebral vasculature $(3,4,49$, 50). These PG increase CBF in the newborn animal (12). Thus, if PG contributed to basal CBF, one would have expected to see a decrease in $\mathrm{CBF}$ after the administration of ibuprofen and naproxen. However, these drugs had no effect on basal CBF.

In contrast to our findings and those of Grice et al. (34), Hoffman et al. (51) reported that ibuprofen caused a decrease in $\mathrm{CBF}$ in the adult goat; Leffler and Busija (21) found that ibuprofen increased $\mathrm{CBF}$ in the newborn pig. The reason for the discrepancy is not clear but may be due to differences in the experimental protocols, including the methods of measuring $\mathrm{CBF}$ and/or anesthetic agents used. Hoffman et al. (51) measured blood flow using electromagnetic probes placed on the internal
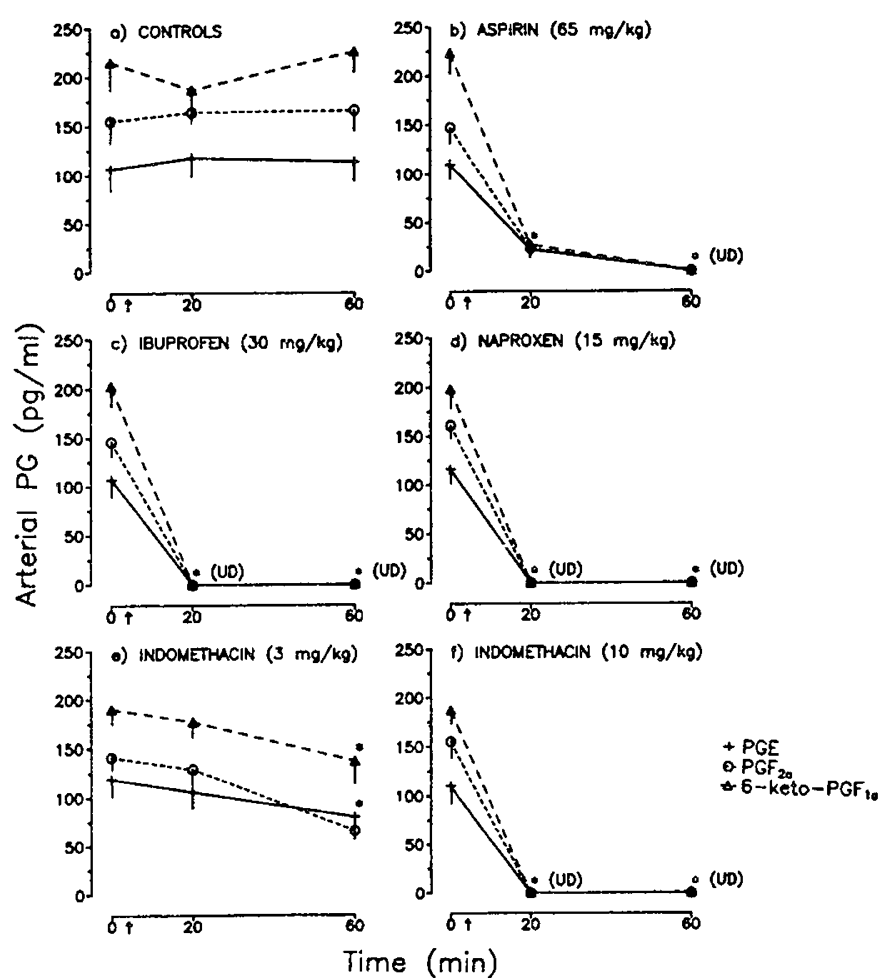

Fig. 3. Effects of aspirin, ibuprofen, naproxen, indomethacin, and vehicle on arterial concentrations of PG of 1- to 3-d-old conscious piglets. The 0 time refers to preinjection values. Aspirin $(n=6)$, ibuprofen $(n=$ 8 ), naproxen $(n=6)$, indomethacin $(n=8$ for $3 \mathrm{mg} / \mathrm{kg}$ and $n=5$ for 10 $\mathrm{mg} / \mathrm{kg})$, and vehicle $(n=8)$ were injected $5 \mathrm{~min}$ later, as indicated by the arrows. Values are mean \pm SEM. $U D$, undetectable levels $(<20 \mathrm{pg} /$ $\mathrm{mL}$ ). ${ }^{*}, p<0.05$ compared with preinjection values (by analysis of variance for repeated measures and comparison among means tests).

maxillary artery; it is possible that they measured in part the effect of ibuprofen on extracerebral blood flow. The data of Leffler and Busija (21) are mentioned in a review, and the experimental conditions are not described.

As discussed above, ibuprofen and naproxen did not alter CBF. On the other hand, the reduction in PG levels after aspirin was administered was accompanied by a significant increase in CBF (Figs. 1-3). This increase in CBF is most likely the result of a rise in cerebral metabolic rate for oxygen, which was not observed with the other NSAID (Table 2) and probably results from an uncoupling of oxidative phosphorylation (31). These effects of aspirin reiterate the importance of cerebral metabolism over the role of $\mathrm{PG}$ on $\mathrm{CBF}$ regulation.

The two doses of indomethacin produced similar changes in CBF but different effects on PG concentrations. Twenty min after the smaller dose of indomethacin $(3 \mathrm{mg} / \mathrm{kg})$ was administered, there was no significant reduction in PG levels, but the cerebral hemodynamic changes were equivalent to those that occurred after the larger dose of indomethacin $(10 \mathrm{mg} / \mathrm{kg})$ was administered, which virtually abolished PG synthesis by $20 \mathrm{~min}$ (Figs. 2 and 3). Furthermore, there was no correlation between the effects of indomethacin on CBF and sagittal sinus PG levels (Fig. 4). The minimal decrease in PG concentrations $1 \mathrm{~h}$ after the lower dose of indomethacin $(3 \mathrm{mg} / \mathrm{kg})$ was administered is in agreement with similar reported changes in brain PG levels up to $4 \mathrm{~h}$ after the same drug dose (23). The effects of indomethacin we observed are also in accord with previous reports, indicating a very rapid and similar decrease (within $2 \mathrm{~min}$ ) in CBF in the animal $(6,15,22)$ and human neonate (19) as well as a decrease in CBF velocity of the human newborn (16-18) before any changes in arterial or cerebral PG occur $(23,24)$. Moreover, our findings are consistent with the action of this drug on various other major vascular beds. In contrast to ibuprofen, meclofena- 


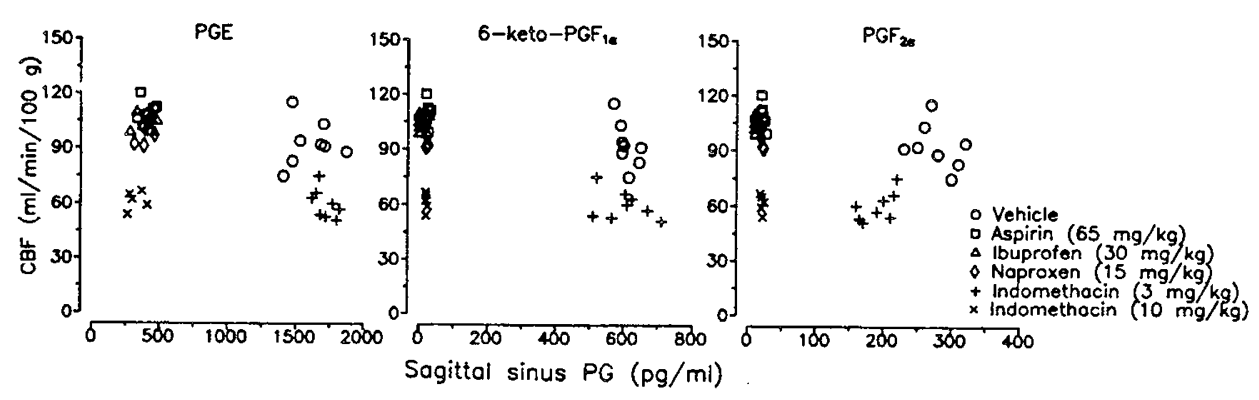

Fig. 4. Relationship between total CBF and sagittal sinus PG levels 20 min after injection of vehicle or NSAID. For all PG, $r=-0.31$ to $0.25, p$ $>0.24$, for individual or combined treatment groups. For the undetectable levels of 6-keto-PGF $\mathrm{P}_{1 \alpha}$ and $\mathrm{PGF}_{2 \alpha}(<20 \mathrm{pg} / \mathrm{mL}) \mathrm{measured} \mathrm{in} \mathrm{the}$ ibuprofen-treated animals, a value of $10 \mathrm{pg} / \mathrm{mL}$ was plotted.

mate, and aspirin, indomethacin has been shown to reduce basal organ (mesenteric, renal, uterine, and cardiac) blood flow (45$48,52,53)$ to the same extent, regardless of its dose (53), and to constrict isolated vessels (29), probably by an action independent of the effects on PG. For instance, indomethacin has been shown to inhibit histamine release (54) and to potentiate the lipoxygenase pathway $(28,55,56)$ in contrast to other $\operatorname{NSAID}(47,56)$.

Several factors are involved in the regulation of basal $\mathrm{CBF}$, including $\mathrm{K}^{+}, \mathrm{Ca}^{2+}$, glutamate, ATP, adenosine, endotheliumderived relaxing factor, endothelin, and eicosanoids, and some of them have opposing actions. Consequently, the release of several of these substances during adaptive physiologic conditions may mask specific effects of one or a group of mediators (57). Thus, the possible interactions of vasoactive factors with opposing effects may explain the failure of a single class of agents, such as PG, to exert a predominant contribution on basal CBF (Figs. 1-3).

In conclusion, the effects of NSAID on cerebral hemodynamics of the newborn animal differ markedly among the various agents, and regardless of the drug or dose, they do not correlate with their effects on PG (Fig. 4). Our data indicate that aspirin and indomethacin appear to exert their acute effects on CBF via mechanisms other than through cyclooxygenase inhibition, whereas ibuprofen and naproxen markedly inhibit PG synthesis without altering $\mathrm{CBF}$. These observations suggest that $\mathrm{PG}$ may not have a critical role in the regulation of basal cerebral hemodynamics in the newborn animal, as has been suggested for other major organs in the adult $(29,32,45-47,52,53,58)$, This, however, does not preclude the important contribution of PG to CBF regulation during adaptive physiologic responses $(1-14,32$, $44,59)$. Finally, our findings clearly indicate, as previously suggested $(20,60)$, that it is necessary to compare the cerebrovascular effects of a range of NSAID before attributing a particular role to the PG.

Acknowledgments. The authors thank Drs. Jean Robillard and Tapan Chatterjee for their valuable comments in reviewing this manuscript.

\section{REFERENCES}

1. Ment LR, Stewart WB, Duncan CC, Scott DT, Lambrecht R 1983 Beagle puppy model of intraventricular hemorrhage: effect of indomethacin on cerebral blood flow. J Neurosurg 58:857-862.

2. Ment LR, Stewart WB, Duncan CC, Pitt BR, Rescigno A, Cole J 1985 Beagle puppy model of perinatal cerebral infarction: acute changes in cerebral blood flow and metabolism during hemorrhagic hypotension. J Neurosurg 63:441447

3. Ment LR, Stewart WB, Duncan CC, Cole J, Pitt BR 1985 Beagle puppy model of perinatal cerebral infarction: acute changes in regional cerebral prostaglandins during hemorrhagic hypotension. J Neurosurg 63:899-904

4. Ment LR, Stewart WB, Duncan CC, Pitt BR, Cole JS 1986 Beagle puppy model of perinatal cerebral infarction: regional cerebral prostaglandin changes during acute hypoxemia. J Neurosurg 65:851-855

5. Ment LR, Stewart WB, Duncan CC, Pitt BR, Cole JS 1987 Beagle pup model of brain injury: regional cerebral blood flow and cerebral prostaglandins. J Neurosurg 67:278-283

6. Leffler CW, Busija DW, Fletcher AM, Beasley DG, Hessler R, Green RS 1985
Effects of indomethacin upon cerebral hemodynamics of newborn pigs. Pediatr Res 19:1160-1164

7. Leffler CW, Busija DW, Beasley DG, Fletcher AM 1986 Maintenance of cerebral circulation during hemorrhagic hypotension in newborn pigs: role of prostanoids. Circ Res 59:562-567

8. Leffler CW, Busija DW 1987 Prostanoids and pial arteriolar diameter in hypotensive newborn pigs. Am J Physiol 252:H687-H691

9. Leffler CW, Beasley DG, Busija DW 1989 Cerebral ischemia alters cerebral microvascular reactivity in newborn pigs. Am J Physiol 257:H266-H271

10. Pourcyrous M, Leffler C, Busija D 1988 Postasphyxial increases in prostanoids in cerebrospinal fluid of piglets. Pediatr Res 24:229-232

11. DeGiulio PA, Roth RA, Mishra OP, Delivoria-Papadopoulos M, Wagerle LC 1989 Effect of indomethacin on the regulation of cerebral blood flow during respiratory alkalosis in newborn piglets. Pediatr Res 26:593-597

12. Chemtob S, Laudignon N, Beharry K, Rex J, Varma DR, Wolfe L, Aranda JV 1990 Effects of prostaglandins and indomethacin on cerebral blood flow and cerebral oxygen consumption of conscious newborn piglets. Dev Pharmacol Ther 14:1-14

13. Chemtob S, Beharry K, Rex J, Varma DR, Aranda JV 1990 Prostanoids determine the range of cerebral blood flow autoregulation of newborn piglets. Stroke 21:774-784

14. Chemtob S, Beharry K, Rex J, Varma DR, Aranda JV 1990 Changes in cerebrovascular prostaglandins and thromboxane as a function of systemic blood pressure: cerebral blood flow autoregulation of the newborn. Circ Res 67:674-682

15. Dahlgren N, Nilsson B, Sakabe T, Siesjö BK 1981 The effect of indomethacin on cerebral blood flow and oxygen consumption in the rat at normal and increased carbon dioxide tensions. Acta Physiol Scand 111:475-485

16. Laudignon N, Chemtob S, Bard H, Aranda JV 1988 Effect of indomethacin on the cerebral blood flow velocity of premature newborns. Biol Neonate 54:254-262

17. Van Bel F, Van de Bor M, Stijnen T, Baan J, Ruys JH 1989 Cerebral blood flow velocity changes in preterm infants after a single dose of indomethacin: duration of its effect. Pediatrics 84:802-807

18. Lundell BPW, Sonesson S-E, Sundell H 1989 Cerebral blood flow following indomethacin administration. Dev Pharmacol Ther 13:139-144

19. Edwards AD, Wyatt JS, Richardson C, Potter A, Cope M, Delpy DT, Reynolds EOR 1990 Effects of indomethacin on cerebral haemodynamics in very preterm infants. Lancet 335:1491-1495

20. Pickard JD 1981 Role of prostaglandins and arachidonic acid derivatives in the coupling of cerebral blood flow to cerebral metabolism. J Cereb Blood Flow Metab 1:361-384

21. Leffler CW, Busija DW 1987 Arachidonic acid metabolites and perinatal cerebral hemodynamics. Semin Perinatol 11:31-42

22. Pickard JD, Mackenzie ET 1973 Inhibition of prostaglandin synthesis and the response of baboon cerebral circulation to carbon dioxide. Nature New Biol 245:187-188

23. Abdel-Halim MS, Sjequist B, Änggård E 1978 Inhibition of prostaglandin synthesis in the rat brain. Acta Pharmacol Toxicol 43:266-272

24. Green RS, Leffler CW 1986 Effect of indomethacin on circulating prostacyclin levels in human neonates. Pediatr Res 20:349(abstr)

25. Dusting GJ, Moncada S, Vane JR 1978 Disappearance of prostacyclin ( $\left.\mathrm{PGI}_{2}\right)$ in the circulation of the dog. Br J Pharmacol 62:414P $-415 \mathrm{P}$

26. Ferreira SH, Vane JR 1967 Prostaglandins: their disappearance from and release into the circulation. Nature 216:868-873

27. Humphrey SJ, Zins GR 1983 The effects of indomethacin on systemic hemodynamics and blood flow in the conscious dog. Res Commun Chem Pathol Pharmacol 39:229-240

28. Dempsey RJ, Roy MW, Meyer K, Cowen DE, Tai H-H 1986 Development of cyclooxygenase and lipoxygenase metabolites of arachidonic acid after transient cerebral ischemia. J Neurosurg 64:118-124

29. Lippton HL, Armstead WM, Hyman AL, Kadowitz PJ 1987 Characterization of the vasoconstrictor activity of indomethacin in the mesenteric vascular bed of the cat. Prostaglandins Leukotrienes Med 27:81-91

30. Toda N, Inoue S, Okamura T, Okunishi H 1988 Mechanism underlying relaxations caused by prostaglandins and thromboxane $\mathrm{A}_{2}$ analog in isolated dog arteries. J Cardiovasc Pharmacol 11:354-362

31. Pickard JD, Rose JE, Shaw M, Strathdee A 1980 The effect of sodium salicylate on cerebral blood flow and metabolism. Br J Pharmacol 68:407-411 
32. Oates JA, FitzGerald GA, Branch RA, Jackson EK, Knapp HR, Roberts LJ 1988 Clinical implications of prostaglandin and thromboxane $\mathrm{A}_{2}$ formation (Part II). N Engl J Med 319:761-767

33. DeGiulio PA, Cameron CF, Mishra OP, Delivoria-Papadopoulos M, Wagerle LC 1990 Differential effect of ibuprofen and indomethacin on cortical prostanoids and pial arteriolar diameter during hypercapnia in newborn piglets. Pediatr Res 27:233(abstr)

34. Grice SC, Chappell ET, Prough DS, Whitley JM, Su M, Watkins D 1987 Ibuprofen improves cerebral blood flow after global cerebral ischemia in dogs. Stroke 18:787-791

35. Dahl H 1986 Naproxen (Naprosyn). Pharmacokinetics: therapeutical relevance and tolerance profile. Cephalalgia 4(suppl):69-75

36. Vesterqvist O, Green K 1989 Effects of naproxen on the in vivo synthesis of thromboxane and prostacyclin in man. Eur $\mathrm{J}$ Clin Pharmacol 37:563-565

37. Leffler CW, Busija DW 1985 Arachidonate metabolism on the cerebral surface of newborn pigs. Prostaglandins 30:811-817

38. Feldberg W, Gupta KP, Milton AS, Wendlandt S 1973 Effect of pyrogen and antipyretics on prostaglandin activity in cisternal CSF of unanaesthetized cats. J Physiol 234:279-303

39. Heymann MA, Payne BD, Hoffman JID, Rudolph AM 1977 Blood flow measurements with radionuclide-labeled particles. Prog Cardiovasc Dis 20:55-76

40. Dray $F$, Charbonnel B, Maclouf J 1975 Radioimmunoassay of prostaglandins $F_{2 \alpha}, E_{1}$, and $E_{2}$ in human plasma. Eur $J$ Clin Invest 5:311-318

41. Blumberg AL, Denny SE, Marshall GR, Needleman P 1977 Blood vesselhormone interactions--angiotensin, bradykinin and prostaglandins. Am Physiol 32:H305-H310

42. Douglas Jr JR, Johnson Jr EM, Marshall GR, Jaffe BM, Needleman P 1973 Stimulation of splenic prostaglandin released by angiotensin and specific inhibition by cysteine ${ }^{8}$-AII. Prostaglandins 3:67-74

43. Needleman P, Minkes MS, Douglas Jr JR 1974 Stimulation of prostaglandin biosynthesis by adenine nucleotides. Circ Res 34:455-460

44. Leffler CW, Mirro R, Armstead WM, Busija DW, Thelin O 1990 Prostanoid synthesis and vascular responses to exogenous arachidonic acid following cerebral ischemia in piglets. Prostaglandins 40:241-248

45. Gaffney GR, Williamson HE 1979 Effect of indomethacin and meclofenamate on canine mesenteric and celiac blood flow. Res Commun Chem Pathol Pharmacol 25:165-168

46. Feigen LP, King LW, Ray J, Beckett W, Kadowitz PJ 1981 Differential effects of ibuprofen and indomethacin in the regional circulation of the dog. Pharmacol Exp Ther 219:679-684

47. Bolli R, Goldstein RE, Davenport N, Epstein SE 1981 Influence of sulfinpyrazone and naproxen on infarct size in the dog. Am J Cardiol 47:841-847

48. Millard RW, Baig H, Vatner S 1977 Renal vascular protection by prostaglandins during hypoxemia in unanesthetized fetal lamb. Pediatr Res 11:395(abstr)

49. Faucher DJ, Magness RR, Mitchell MD, Roy T, Rosenfeld CR 1987 Comparisons of fetal vascular prostaglandin production. Pediatr Res 21:384A(abstr)

50. White RP, Hagen AA 1982 Cerebrovascular actions of prostaglandins. Pharmacol Ther 18:313-331

51. Hoffman WE, Albrecht RF, Pelligrino D, Miletich DJ 1982 Effects of prostaglandins on the cerebral circulation in the goat. Prostaglandins 23:897-905

52. Gerkens JF, Shand DG, Flexner C, Nies AS, Oates JA, Data JL 1977 Effect of indomethacin and aspirin on gastric blood flow and acid secretion. $\mathrm{J}$ Pharmacol Exp Ther 203:646-652

53. Naden RP, Iliya CA, Arant BS, Gant NF, Rosenfeld CR 1985 Hemodynamic effects of indomethacin in chronically instrumented pregnant sheep. Am J Obstet Gynecol 151:484-493

54. König W, Brom J, Schönfeld, Knöller J, Stüning M 1987 Effect of tenoxicam and indometacin on the release of histamine, prostaglandin $\mathrm{E}_{2}$ and leukotrienes from various cells. Arzneim-Forsch 37:296-299

55. Jugdutt BI, Hutchins GM, Bulkley BH, Pitt B, Becker LV 1979 Effect of indomethacin on collateral blood flow and infarct size in the conscious dog. Circulation 59:734-743

56. Docherty JC, Wilson TW 1987 Indomethacin increases the formation of lipoxygenase products in calcium ionophore stimulated human neutrophils. Biochem Biophys Res Comm 148:534-538

57. Pickard JD 1987 Ionic and eicosanoid regulation of cerebrovascular smooth muscle contraction. In: Wood JH (ed) Cerebral Blood Flow: Physiologic and Clinical Aspects. McGraw-Hill, New York, pp 131-144

58. Sakanaski M, Alaki H, Yonemium K 1980 Indomethacin-induced contractions of dog coronary arteries. J Cardiovasc Pharmacol 2:657-665

59. Chemtob S, Beharry K, Barna T, Aranda JV 1990 Prostanaoids contribute significantly to the post-ischemic compromise in autoregulation of periventricular cerebral blood flow in the newborn piglet. Pediatr Res 27:202(abstr)

60. Quintana A, Raczka E, Quintana MA 1988 Effects of indomethacin and diclofenac on cerebral blood flow in hypercapnic conscious rats. Eur $J$ Pharmacol 149:385-388 